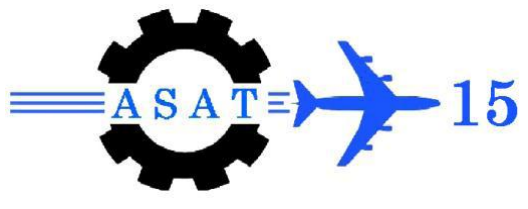

\title{
Effect of Processing Parameters on the Mechanical and Structure Properties of 93W-4.9Ni-2.1Fe Tungsten Heavy Alloy
}

\author{
\{A. S. Abdallah*, A. Fayed, G. Abdou, M.T. Sallam $\}^{\dagger}$
}

\begin{abstract}
The objective of this experimental study is to investigate the effect of the main compaction and sintering parameters on the micro-structure and the mechanical properties of the liquid phase sintered $93 \%$ wt.W-4.9\%wt.Ni-2.1\%wt.Fe tungsten heavy alloy aiming at determining the optimum values of these parameters.

Elemental powders were mixed using planetary mixer for 5 hours to ensure suitable homogeneity. Uni-axial compaction was applied to obtain standard tensile and impact specimens using compaction pressures ranging from 50MPa to $300 \mathrm{MPa}$. Vacuum liquid phase sintering was carried out under different temperatures from $1460^{\circ} \mathrm{C}$ up to $1500^{\circ} \mathrm{C}$ and sintering time from 30 minutes up to 120 minutes.

The effect of these parameters was characterized in terms of density, hardness, impact resistance and tensile properties. Microstructure variations, notably grain size, matrix volume fraction and contiguity were measured and used to explain the effect of sintering temperature and time on the properties.

The obtained results indicated that optimum hardness and impact resistance can be obtained at a compaction pressure of about $200 \mathrm{MPa}$. As the sintering temperature increases, the grain size and volume fraction of matrix increase, while the contiguity decreases. As a result of these micro-structural changes, strength and hardness decrease. On the other hand, ductility and impact resistance increase with sintering temperature to some maximum at $1480^{\circ} \mathrm{C}$. At further increase of this temperature, grain growth becomes the dominant factor leading to a sensible decrease in all properties. The effect of sintering time on mechanical properties is related to grain growth and pore coarsening mechanisms. It is generally observed that strength and ductility decrease after sintering over 90 minutes at $1480^{\circ} \mathrm{C}$. It was also noticed that the ductility is more sensitive to sintering time and is reduced sharply with prolonged holding at the sintering temperature.

It can be concluded that the mechanical properties of tungsten heavy alloys are sensitive to the processing cycle and are adversely affected by residual porosity. Moreover, tungsten grain size plays an important role in dictating the failure mode during tensile testing. If tungsten grain size is large interface failure is predominant. However, as the grain size decreases, fracture mode changes gradually from interface failure to matrix failure and then to tungsten grain cleavage failure.
\end{abstract}

Keywords: Optimization, processing parameters, liquid phase sintering, tungsten heavy alloy. 


\section{Introduction}

Tungsten heavy alloys are two phase metal matrix composites produced by liquid phase sintering from $\mathrm{W}-\mathrm{Ni}-\mathrm{Fe}, \mathrm{W}-\mathrm{Ni}-\mathrm{Co}$ or $\mathrm{W}-\mathrm{Ni}-\mathrm{Cu}$ elemental powder mixes. In this process, the compact is pressed by either uni-axial press or cold isostatic press (CIP), and sintered in a furnace with a continuous flow of hydrogen or under vacuum. During sintering, the lower melting elements melt and form the matrix that bonds the un-melted $\mathrm{W}$ particles together. Some amount of $\mathrm{W}$ also gets dissolved in the matrix and gets re-precipitated on the primary W particles, which renders the tungsten grains rounded and larger in size.

There are two discrete interfaces present in tungsten heavy alloys, that are the boundary between the tungsten and the matrix, and the interface between one tungsten particle and the other particles, the later defines the contiguity of tungsten grains in tungsten alloy defined as the relative fraction of tungsten-tungsten interfacial area. These two interfaces have significant effects on the fracture behavior and mechanical properties of tungsten heavy alloys.

Although polycrystalline tungsten normally is brittle at room temperature, the matrix imparts ductility to the composite. Also, the ductile matrix effectively redistributes the stress during deformation so that crack propagation is hindered. The typical mean tungsten grain size varies from 20 to 60 microns depending on the initial particle size, volume fraction of tungsten, sintering temperature and sintering time.

The combination of high density and high strength associated with the bcc tungsten phase, high ductility attributed to the fcc matrix, conductivity and corrosion resistance makes the tungsten heavy alloys unique in the field of materials. These alloys are used in applications such as kinetic energy penetrators, radiation shielding, counter balance, vibrational damping devices, and other military and civil applications.

Previous researches into the mechanical properties of heavy alloys have identified that the properties of these alloys are sensitive to many factors including processing and alloy composition. And are degraded by residual porosity, incomplete oxide reduction, intermetallic precipitation, impurity segregation, hydrogen embrittlement and incomplete densification which is still the primary concern.

Phosphorus and Sulfur are two important impurities in tungsten heavy alloys. C.Lea, B.C.Muddle, and D.V.Edmonds [1] reported that Phosphorus and Sulfur segregated at tungsten-matrix interfaces. Their presence reduces boundary cohesion and promotes brittle interfacial failure on impact loading leading to embrittlement. Proper post-sintering heat treatment, however, avoids segregation of impurities at the tungsten-matrix interface and allows the impurities to remain homogeneously distributed throughout the matrix [2]. Therefore, the post-sintering heat treatment causes great improvement in mechanical properties of tungsten heavy alloys [3].

German and Bourguignon [4,5] reported that the Ni/Fe ratio of $7: 3$ was optimal. The Fe to $\mathrm{Ni}$ ratio plays an important role in determining the properties of tungsten heavy alloys. Avoiding the formation of brittle intermettallic phases at the interfaces is the most important factor that should be considered in selecting $\mathrm{Ni}$ to $\mathrm{Fe}$ ratio. For example, the work reported by Penrice and Bost [2] reveal that an intermetallic phase $\mathrm{Fe}_{7} \mathrm{~W}_{6}$ forms at low $\mathrm{Ni}$ to $\mathrm{Fe}$ ratios, whereas at ratios higher than $4: 1, \mathrm{Ni}_{2} \mathrm{~W}, \mathrm{NiW}$ and $\mathrm{Ni}_{4} \mathrm{~W}$ intermetallic phases form. It has been generally observed that the highest strength is obtained at tungsten concentrations of approximately 93\%wt. with a 7:3 Ni to Fe ratio. In related work, Wittenauer and Nieh [6] indicated that the selection of $\mathrm{Ni}$ to $\mathrm{Fe}$ ratio of 7:3 effectively prevents the formation of brittle intermetallic phases.

It is known that the mechanical properties, in particular ductility, of tungsten heavy alloys are extremely sensitive to sintering conditions and post sintering heat treatments [2]. In general, processing conditions influence densification, porosity, grain growth and contiguity, all of which eventually affect the mechanical properties of the alloys. 
The effects of sintering temperature on mechanical properties are essentially attributed to the resulting variations in grain size, matrix volume fraction and contiguity. As reported by R.M.German [8], high sintering temperature leads to faster tungsten grain growth rate. Moreover, the effects of sintering time on mechanical properties are related to grain growth and pore coarsening mechanisms. Sintering for 90 minutes resulted in fully dense samples with rounded grains. Over this time period, the yield strength decreases due to grain growth, while the tensile strength and elongation are degraded due to an increase in porosity. Also, with increased sintering time, residual pores coalesce and grow, causing a decrease in the final sintered density.

The main focus of this study is to investigate and identify trends in microstructure relative to variations in sintering parameters and the influence of microstructure change on the mechanical properties of tungsten heavy alloys.

\section{Experimental Procedure}

\subsection{Characteristics of Used Powders}

The main constituents of the adopted tungsten heavy metal alloy are commercial pure tungsten, nickel and iron powders. The tungsten powder was fabricatred by reducing tungsten oxide in hydrogen atmosphere and suuplied by Buffalu tungsten incorporation, while, the nickel and iron powders were fabricated by carbonel method and supplied by MHC company. The different powders were chemically analyzed by X-ray fluorescence (XRF) technique to determine their composition and purity. The obtained chemical compositions are illustrated in Table (1).

Table 1. Chemical Composition of the Used Powders (in wt.\%)

\begin{tabular}{c|c|c|c|c|c|c|c|c|c|c}
\hline \hline Powders & $\mathrm{W} \%$ & $\mathrm{Ni} \%$ & $\mathrm{Fe} \%$ & $\mathrm{Si} \%$ & $\mathrm{Al} \%$ & $\mathrm{Mg} \%$ & $\mathrm{Ca} \%$ & $\mathrm{Ga} \%$ & $\mathrm{P} \%$ & $\mathrm{~S} \%$ \\
\hline Tungsten powder & 99.825 & -- & -- & -- & -- & -- & 0.036 & 0.021 & 0.062 & 0.056 \\
\hline Nickel powder & -- & 99.496 & 0.132 & 0.204 & 0.115 & 0.046 & -- & -- & 0.003 & 0.003 \\
\hline Iron powder & -- & -- & 99.396 & 0.335 & 0.172 & 0.062 & 0.02 & -- & 0.01 & 0.005 \\
\hline \hline
\end{tabular}

The apparent densities of these powders were measured by Hall flowmeter, and the tap densities were determined after standard tapping. The results of both densities were compared with the values of the theoritical densities as shown in Table (2).

Table 2. Theoretical, Apparent and Tap Densities of the Used Powders

\begin{tabular}{c|c|c|c}
\hline \hline Measured density & $\begin{array}{c}\text { Tungsten } \\
\text { powder }\end{array}$ & $\begin{array}{c}\text { Nickel } \\
\text { powder }\end{array}$ & $\begin{array}{c}\text { Iron } \\
\text { powder }\end{array}$ \\
\hline Theoretical density, g/cc & 19.3 & 8.9 & 7.9 \\
\hline Apparent density, g/cc & 3.6 & 0.93 & 1.4 \\
\hline Tap density, g/cc & 6.75 & 1.65 & 2.63 \\
\hline \hline
\end{tabular}


The particle size and distribution of the used powders were measured by laser light scattering technique (LLST), and are represented in Fig.1(a-c). Moreover, this Figure demonstrates the different cumulative histograms for the used powders. It can be noted that Tungsten, Nickel and Iron powders have an average particle size of about 1-2 $\mu \mathrm{m}, 1-3 \mu \mathrm{m}$ and $3-5 \mu \mathrm{m}$ respectivily as shown in Table (3).

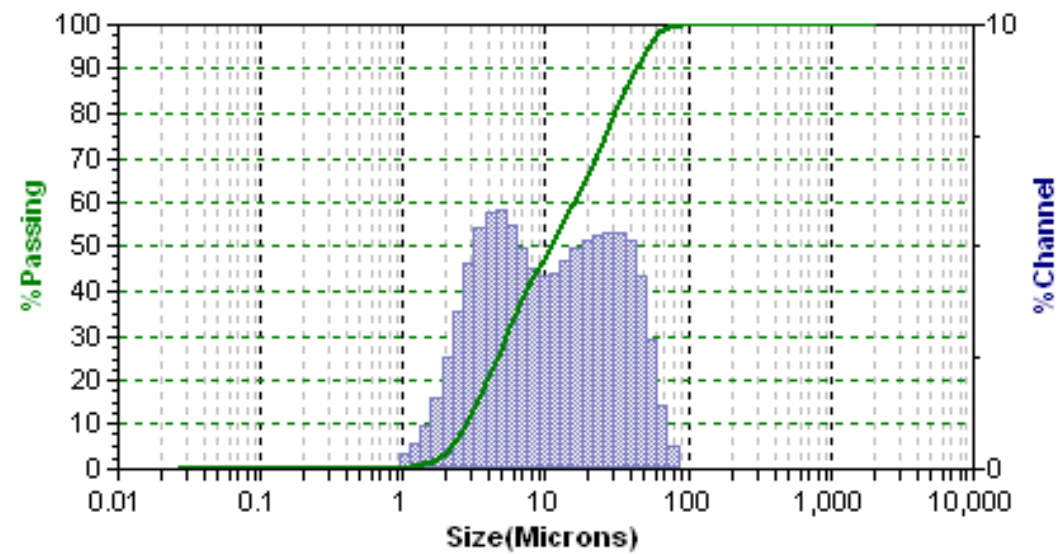

(a)

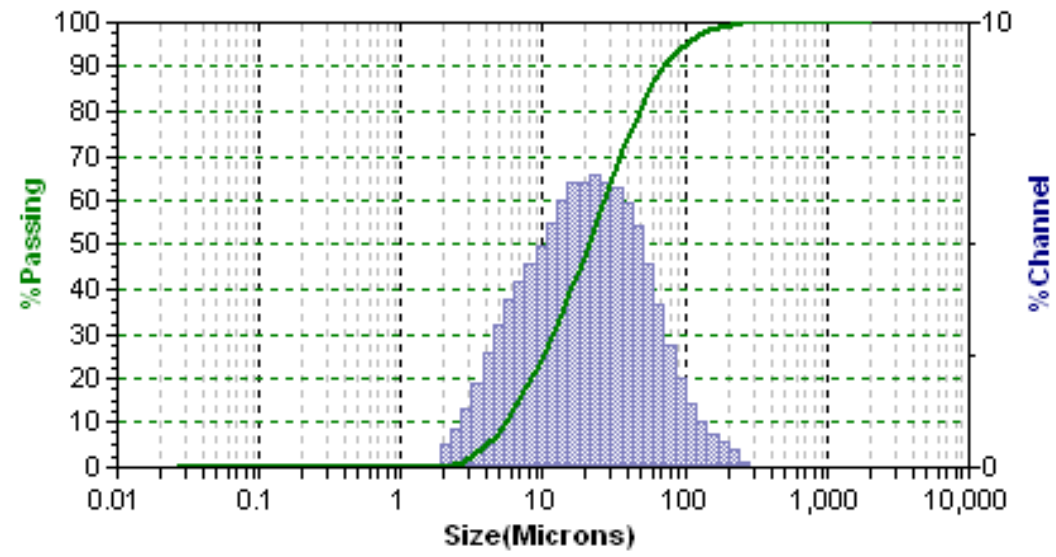

(b)

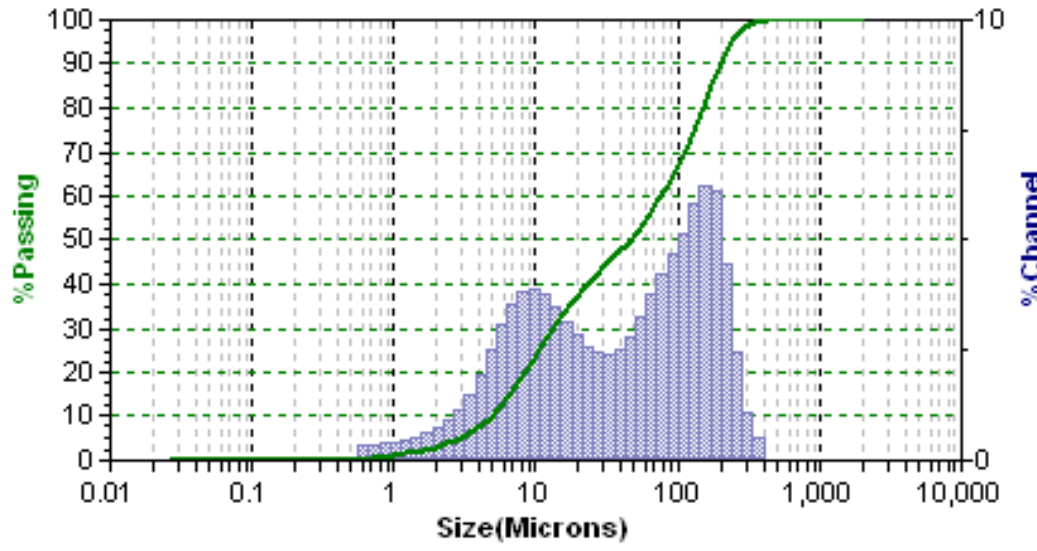

(c)

Fig.(1) Histogram of the as received (a) tungsten, (b) nickel, and (c) iron powders 
Table 3. Average and cumulative particle size of the used powders

\begin{tabular}{c|c|c|c}
\hline Powders & $\begin{array}{c}\text { Tungsten } \\
\text { powder }\end{array}$ & $\begin{array}{c}\text { Nickel } \\
\text { powder }\end{array}$ & $\begin{array}{c}\text { Iron } \\
\text { powder }\end{array}$ \\
\hline Average Particle size, $\mu \mathrm{m}$ & $1-2$ & $1-3$ & $3-5$ \\
\hline $\mathrm{D}_{10}$ & 2.8 & 5.42 & 4.89 \\
\hline \hline
\end{tabular}

The morphology of these powders was revealed by SEM as shown in Fig.2(a-c). Tungsten powder appered to have polygonal shape, and nickel powder is of spongy shape, while the iron powder shows nearly spherical shape.

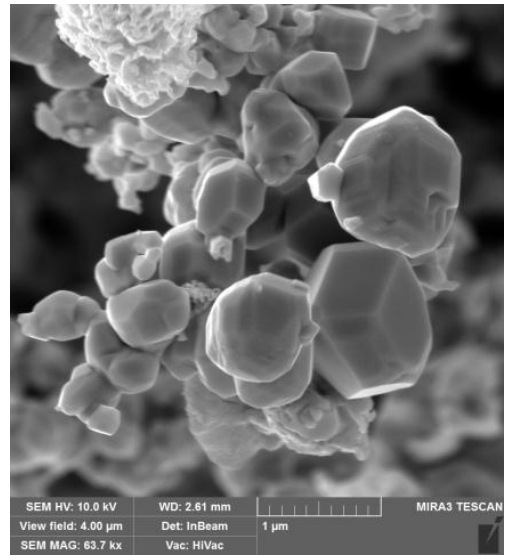

(a)

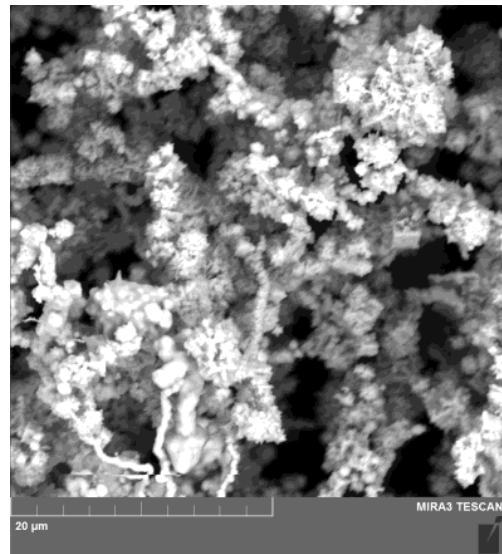

(b)

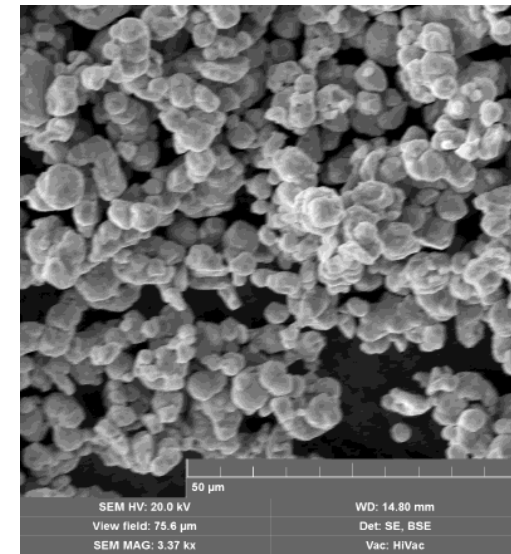

(c)

Fig. (2). SEM Images of as Received (a) Tungsten, (b) Nickel, and (c) Iron

\subsection{Preparation of Sintered Specimens}

The production of sintered specimens was achieved by conventional powder metallurgy technique. Elemental powders of tungsten, nickel and iron were mixed to produce a mixture with the composition of $93 \mathrm{~W}-4.9 \mathrm{Ni}-2.1 \mathrm{Fe}$ in weight percent. This content of tungsten is widely used to achieve the highest mechanical properties, while, the Ni to Fe ratio is typically maintained to $7 / 3$ to avoid the formation of brittle intermetallic phases $[9,10,4,5]$. The different powders were mixed using planetary mixer for 5 hours, to insure homogeneous mixing. To improve compressibility during uni-axial compaction, $0.5 \%$ paraffin wax was added to the mixture for decreasing friction among particles. The powders were then consolidated into green compacts with about $50 \%$ of the theoretical density by uni-axial die pressing. Two single action dies with the required dimensions were used to obtain the shape and size of tensile and impact standard test specimens. Compaction pressure was varied from $50 \mathrm{MPa}$ up to $300 \mathrm{MPa}$. Zinc sterate was used as a die wall lubricant during compaction. Sintering was carried out under continuous primary vacuum atmosphere in a vacuum batch sintering furnace with graphite heating elements. Sintering temperature was varied from $1460^{\circ} \mathrm{C}$ up to $1500^{\circ} \mathrm{C}$, while sintering time was changed from $30 \mathrm{~min}$. up to $120 \mathrm{~min}$. The sintering cycle applied for all experiments is shown in Fig.(3), it consists of the following steps: 
- Heat up to $250^{\circ} \mathrm{C}$ at $3{ }^{\circ} \mathrm{C} / \mathrm{min}$ and holding for $15 \mathrm{~min}$. for wax removal.

- Heat up to $600^{\circ} \mathrm{C}$ at $6^{\circ} \mathrm{C} / \mathrm{min}$. and holding at $600^{\circ} \mathrm{C}$ for $30 \mathrm{~min}$. for internal stress relief.

- Heat up to $1000^{\circ} \mathrm{C}$ at $6^{\circ} \mathrm{C} / \mathrm{min}$. and holding at $1000^{\circ} \mathrm{C}$ for $30 \mathrm{~min}$. to facilitate partial solid phase sintering.

- Heat up to sintering temperature $\left(1460^{\circ} \mathrm{C}-1500^{\circ} \mathrm{C}\right)$ at $6^{\circ} \mathrm{C} / \mathrm{min}$. and holding for the sintering time (30min.-120min.).

- Slow cooling at $3^{\circ} \mathrm{C} / \mathrm{min}$ down to $1420^{\circ} \mathrm{C}$ to avoid cracks during solidification shrinkage followed by furnace cooling.

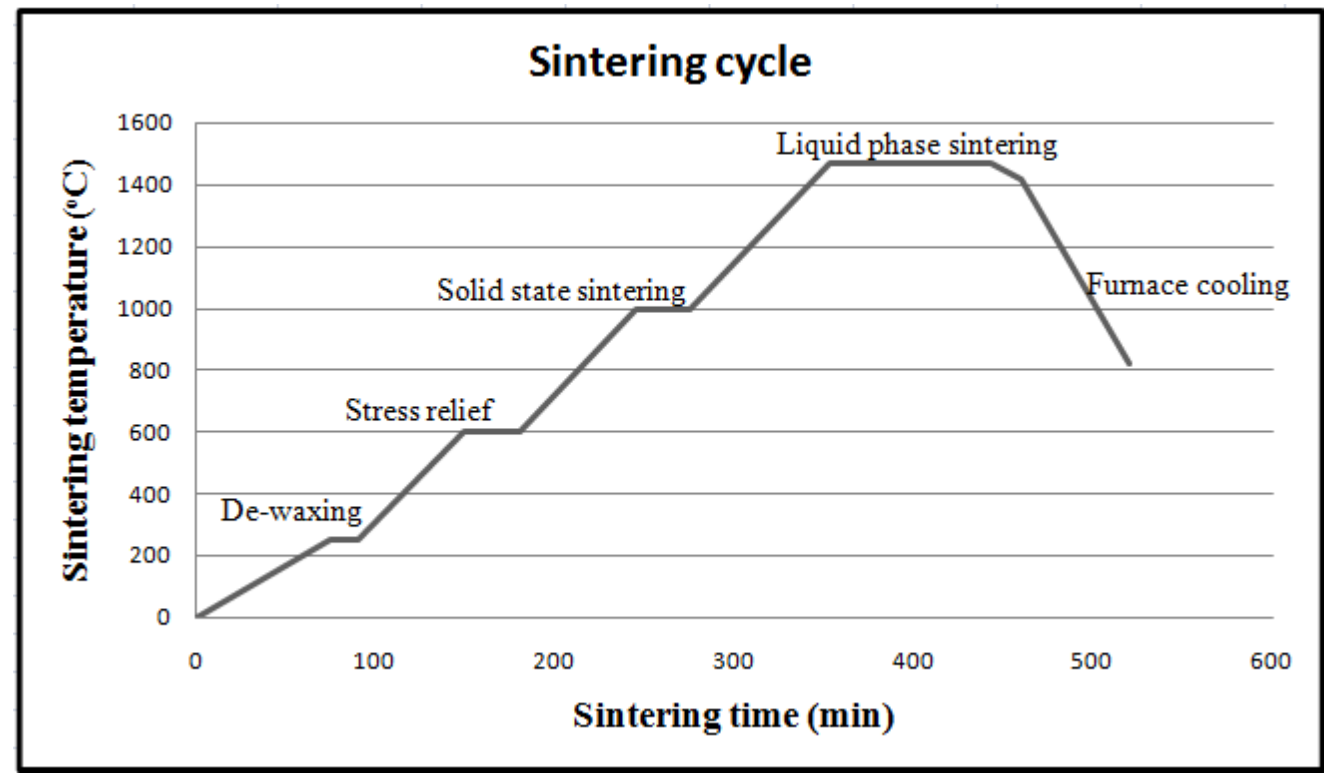

Fig. (3) Sintering cycle used for all samples.

\subsection{Characterization of Samples}

The densities of the sintered specimens were measured by the Archimedes water immersion method [11]. Quasi-static tensile testing was carried out using an Instron testing machine model 8032, under a load control mode of $0.15 \mathrm{KN} / \mathrm{Sec}$. The stress-strain diagram was recorded on standard test specimens, prepared according to the ASTM standard E8M with gage length $25.4 \mathrm{~mm}$. Charpy impact test was conducted using unnotched standard impact specimens according to ASTM standard E23. The energy absorbed by specimens per unit area was taken as a measure of the impact resistance. The fractured surfaces of the impact tested specimens were observed using scanning electron microscope type MIRA3 TESCAN. The hardness of the produced specimens under different conditions was measured by Vickers hardness tester type Instron Wilson-Wolpert model Tukon $2100 \mathrm{~B}$, using $30 \mathrm{Kg}$ load. An average of three hardness readings, for each specimen, was determined. Samples were prepared for microstructural evaluation by cutting, mounting, grinding and polishing to a $0.3 \mu \mathrm{m}$ surface finish using standard metallographic procedures. The microstructures were observed by scanning electron microscope (SEM) after etching using ( $\mathrm{HNO}_{3} 15 \mathrm{ml}$, HF $3 \mathrm{ml}$, $\mathrm{H}_{2} \mathrm{O} 80 \mathrm{ml}$ ) as an etchant [12]. The micrographs were quantitatively analyzed using an image analyzer to measure the size and volume fraction of tungsten particles, the matrix fraction, the connectivity and the contiguity, which greatly influence the properties of tungsten heavy alloys. 


\section{Results and Discussion}

\subsection{Microstructure}

The microstructure of the produced specimens, at different sintering temperatures and times are presented in Fig.(4) and Fig.(5). In this study, four micrographs (800X) were taken from each sample, at different locations for analysis. Each micrograph was analyzed separately, and the mean values of the different microstructural parameters were determined. Edge effects were avoided by considering only grains and necks completely included in each viewing frame. An image analysis software (Image J) was used to determine the grain size, connectivity, contiguity and different phase fractions. Table (4) summarizes the microstructural parameters measured at different sintering temperatures and at a fixed sintering time of 90 minutes.

Table (4) Mean values of the measured microstructural parameters measured at different sintering temperatures and at a fixed sintering time of 90 minutes

\begin{tabular}{l|c|c|c}
\hline Sintering temperature $\left({ }^{\circ} \mathrm{C}\right)$ & $1460^{\circ} \mathrm{C}$ & $1480^{\circ} \mathrm{C}$ & $1500^{\circ} \mathrm{C}$ \\
\hline Grain size $(\mu \mathrm{m})$ & 22.28 & 25.89 & 29.12 \\
\hline Connectivity & 2.63 & 2.25 & 2.1 \\
\hline Contiguity & 0.35 & 0.31 & 0.29 \\
\hline Matrix volume fraction $\%$ & 13.22 & 14.05 & 14.98 \\
\hline
\end{tabular}

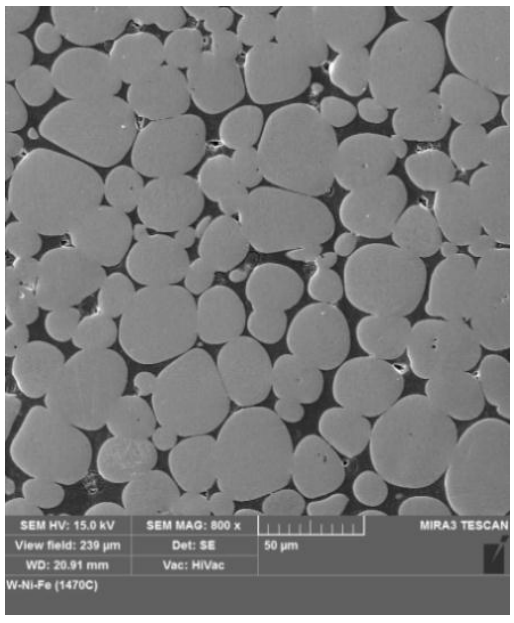

(a)

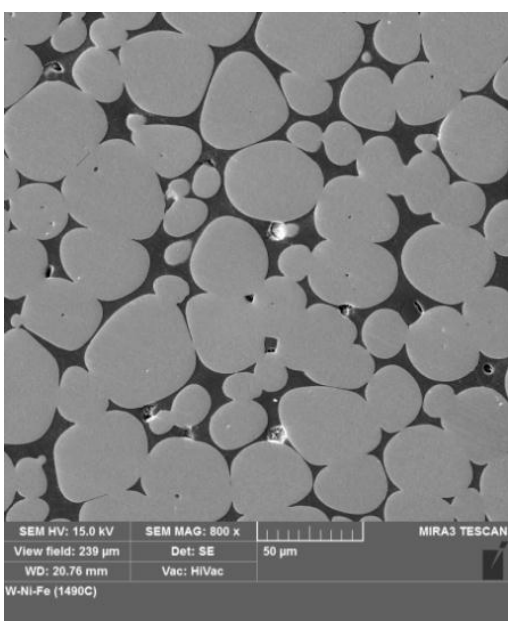

(b)

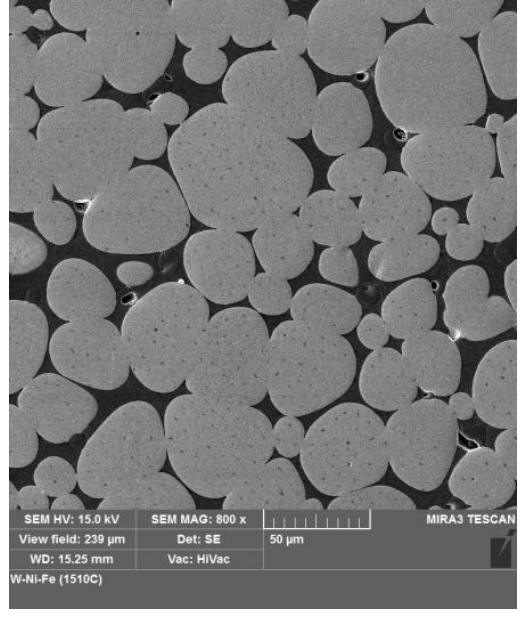

(c)

Fig.(4). SEM images for $93 \% \mathrm{~W}-4.9 \% \mathrm{Ni}-2.1 \% \mathrm{Fe}$ alloy compacted at $200 \mathrm{MPa}$ and sintered for 90 minute at different at temperatures (a) $1460^{\circ} \mathrm{C}$, (b) $1480^{\circ} \mathrm{C}$, and (c) $1500^{\circ} \mathrm{C}$ using magnification $800 \mathrm{X}$

Table (5) summarizes the microstructural parameters measured at a fixed sintering temperature of $1500^{\circ} \mathrm{C}$ for different sintering times.

Table (5) Mean values of the measured microstructural parameters measured at a fixed sintering temperature of $1500^{\circ} \mathrm{C}$ for different sintering times

\begin{tabular}{l|c|c|c}
\hline \multicolumn{1}{c|}{ sintering time $(\mathrm{min})$} & 30 minute & 90 minute & 120 minute \\
\hline Grain size $(\mu \mathrm{m})$ & 19.76 & 29.12 & 31.88 \\
\hline Connectivity & 3.2 & 2.1 & 1.95 \\
\hline Contiguity & 0.48 & 0.29 & 0.26 \\
\hline Matrix volume fraction & 12.393 & 14.98 & 15.47 \\
\hline
\end{tabular}




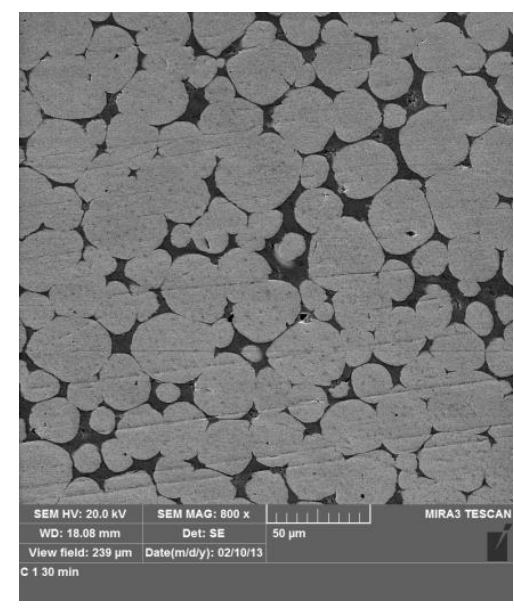

(a)

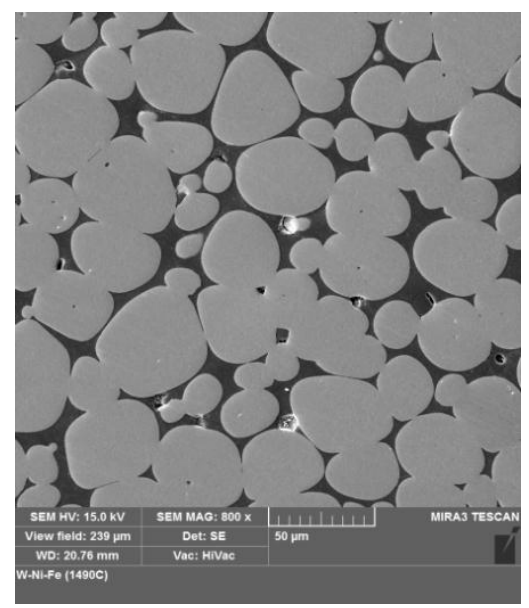

(b)

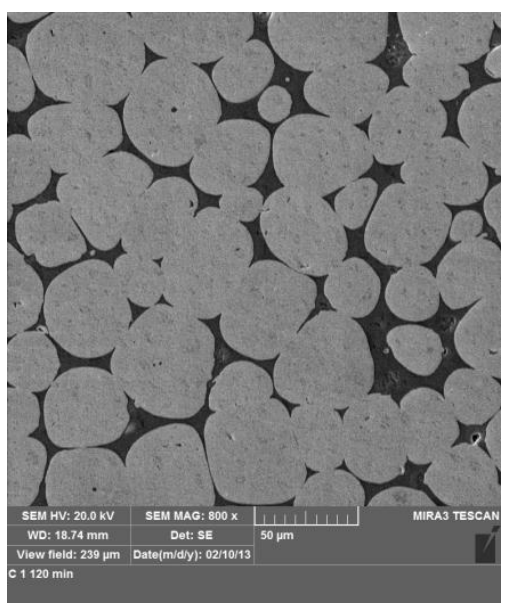

(c)

Fig.(5). SEM images for $93 \% \mathrm{~W}-4.9 \% \mathrm{Ni}-2.1 \% \mathrm{Fe}$ alloy sintered at temperature $1500 \mathrm{C}$, $200 \mathrm{MPa}$ compaction pressure for (a) 30 minute, (b) 90 minute and (c) 120 minute using magnification $800 \mathrm{X}$

It can be noted that:

- The mean grain size increases with increasing sintering temperature and time as shown in Fig.(6) and Fig.(7). At higher sintering temperatures and prolonged sintering times, diffusion is enhanced which directly leads to higher tungsten grain growth rate. Growth of grains occurs either by solution-reprecipitation process through the matrix or solid state diffusion along contacts between tungsten particles [13]. In the first growth mechanism, smaller tungsten particles are dissolved, in a first stage, in the matrix, then reprecipitated on the larger grains, in another stage. The solubility of a tungsten grain varies inversely with the grain size; hence, small grains preferentially dissolve in the liquid phase and over time, the grain count decreases while the grain size increases. Beside grain growth, this mechanism, also allows grain shape accommodation which contributes for better packing of the tungsten grains and release of liquid to fill any remaining pores. While, in the second growth mechanism, grain coarsnening takes place through necking and bridging of tungsten particles by diffusion in the solid state.

- Matrix volume fraction increases with increasing sintering temperature and time as shown in Fig.(6) and Fig.(7), This can be attributed to the higher solubility of tungsten in the matrix. The binary phase diagram of Ni-W [14] indicates that tungsten is much more soluble in nickel, and forms an FCC solid solution, than the solubility of nickel in tungsten. Moreover, both metals form a serious of intermetallic compounds at room temperature.

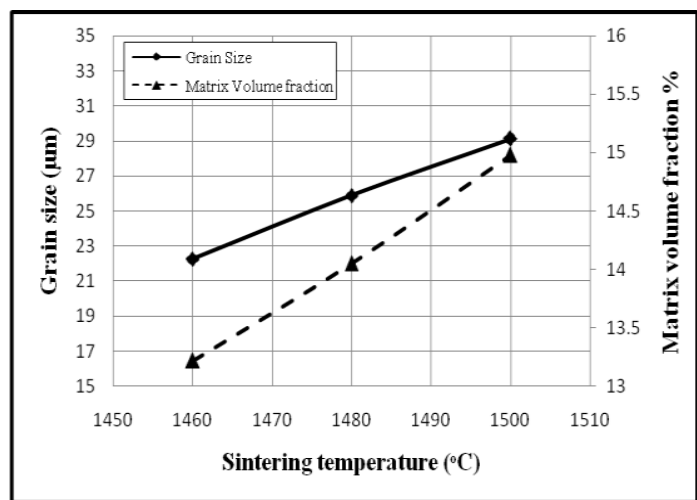

Fig.(6). Grain size and matrix volume fraction variation with sintering

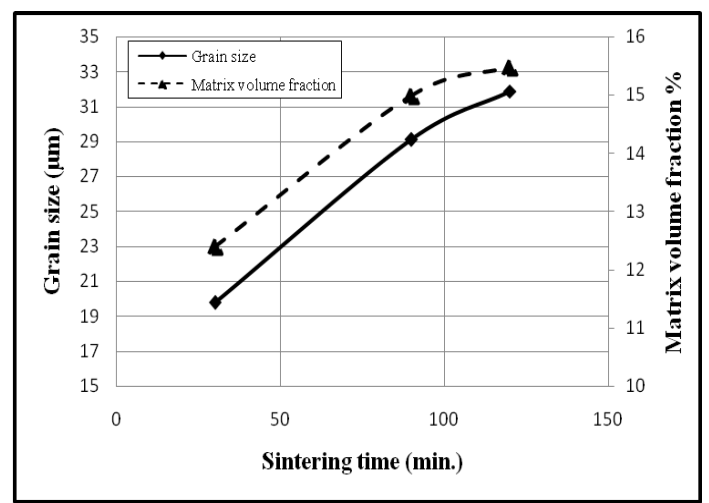

Fig.(7). Grain size and matrix volume fraction variations with sintering time 
- The contiguity decreases with increasing both sintering temperature and time as shown in Fig.(8) and Fig.(9). This can be principally attributed to, from one hand, the decrease in the dihedral angle due to the flattening and growth of tungsten grains, and from the other hand, the increase of the matrix volume fraction as a dominant factor. This leads to decreasing the ratio between contact areas and the total increased surface area for a given tungsten particle, consequently, contiguity decreases.

- Grain connectivity was measured automatically by counting the number of contacting grains and the results were given in table (2). Similar to contiguity, it is found that the connectivity slightly decreases with increasing both sintering time and temperature as shown in in Fig.(8) and Fig.(9).

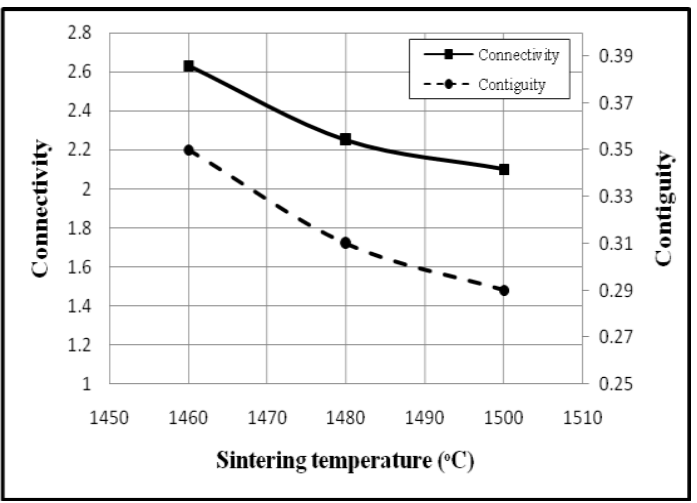

Fig.(8). Contiguity and connectivity variations with sintering temperature

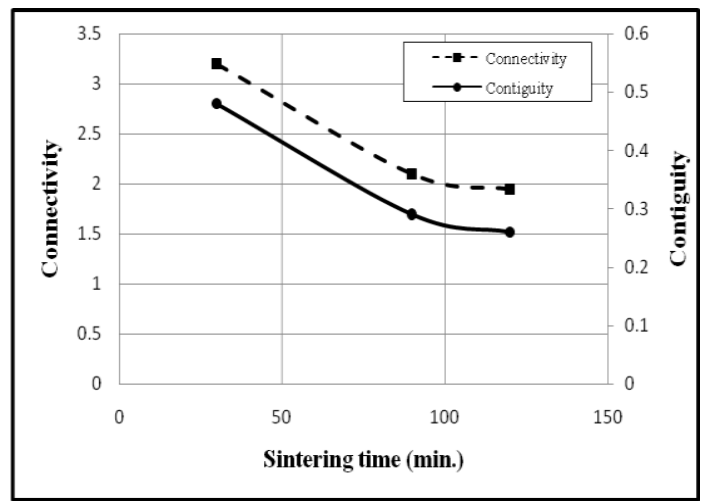

Fig.(9). Contiguity and connectivity variations with sintering time

Quantitative EDS analysis measured on the matrix of $\mathrm{W}-4.9 \mathrm{Ni}-2.1 \mathrm{Fe}$ alloy after sintering at $1460^{\circ} \mathrm{C}$ for $90 \mathrm{~min}$., in different locations, indicates the presence of tungsten as shown in Fig.(10). The analysis shows that the average composition of the matrix phase contains about $9.77 \% \mathrm{~W}-26.01 \% \mathrm{Fe}-64.23 \% \mathrm{Ni}$. This confirms that during liquid phase sintering a substantial amount of tungsten dissolves in the matrix, which decreases the contiguity and connectivity and increases the matrix volume fraction. Moreover, the solubility of tungsten strengthens the matrix by solid solution strengthening mechanism.

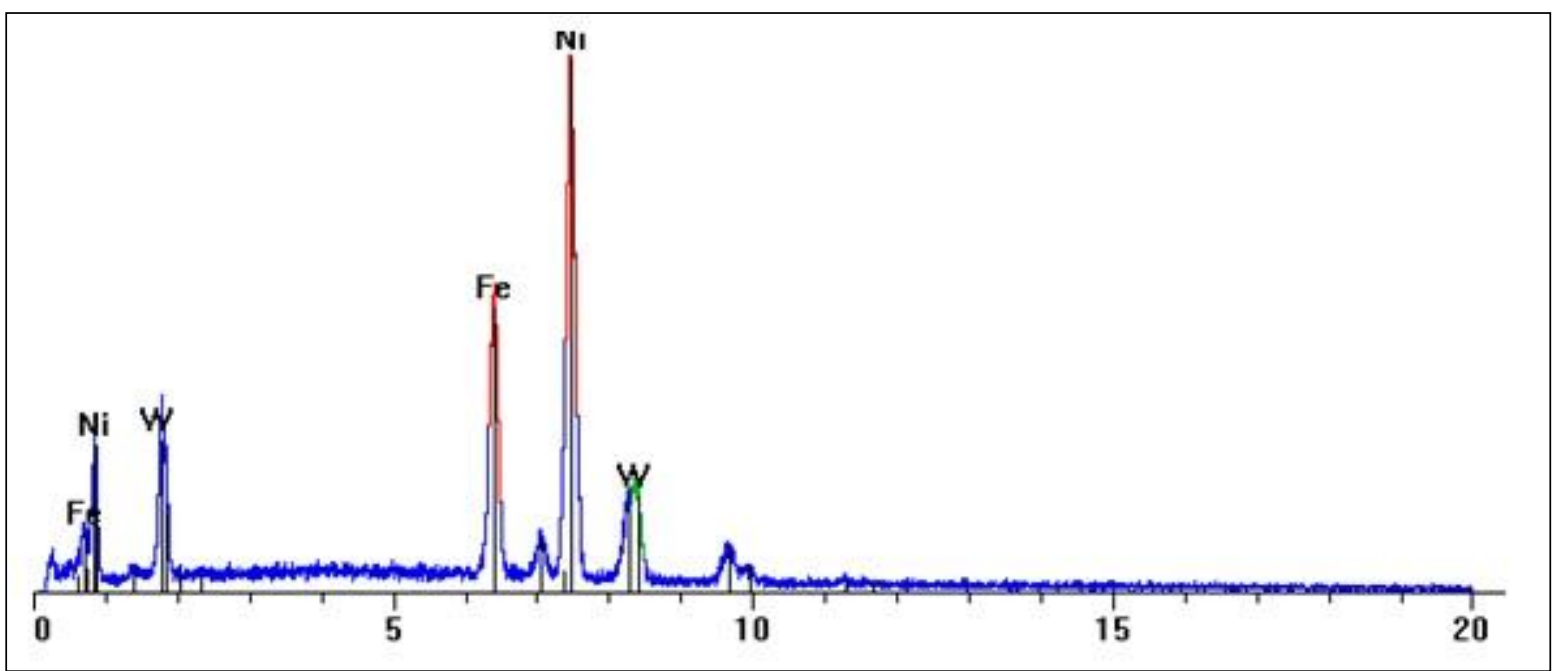

Fig.(10) EDS spectrum of matrix phase in 93W-4.9Ni-2.1Fe 


\subsection{Mechanical Properties}

Mechanical characteristics, particularly, tensile strength, ductility, hardness and impact resistance were taken as a measure to evaluate the optimum processing parameters (compaction pressure-sintering temperature and time). Furthermore, the inter-relation and the analogy between these mechanical properties and the obtained microstructure, in each case, was determined.

\subsubsection{Tensile properties}

The stress-strain curves for, the adopted tungsten heavy metal alloy, after compaction under various pressures ranging from50 up to $300 \mathrm{MPa}$, and sintered at different temperatures namely, $1460^{\circ} \mathrm{C}, 1480^{\circ} \mathrm{C}$ and $1500^{\circ} \mathrm{C}$ for 90 min. are shown in Figs.(10,11 and 12).

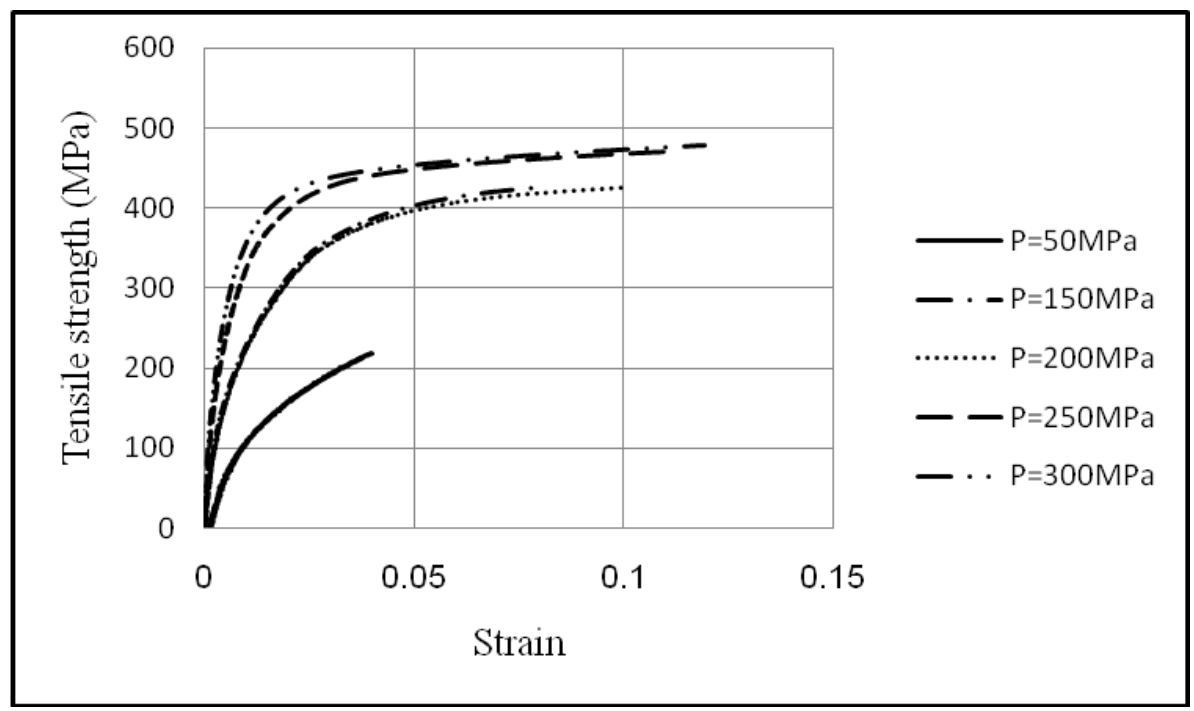

Fig.(10) Effect of compaction pressure on the stress strain diagrams of $\mathrm{W}-4.9 \mathrm{Ni}-2.1 \mathrm{Fe}$ alloy sintered at $1460^{\circ} \mathrm{C}$ for $90 \mathrm{~min}$.

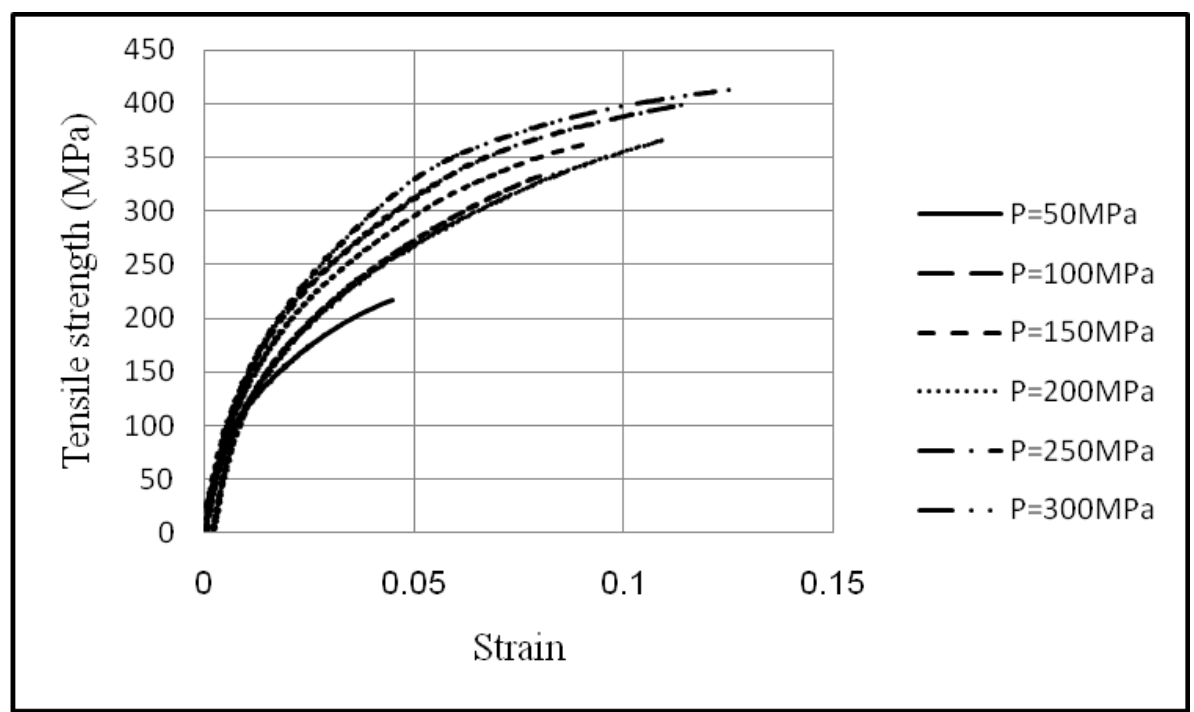

Fig.(11) Effect of compaction pressure on the stress strain diagrams of W-4.9Ni-2.1Fe alloy sintered at $1480^{\circ} \mathrm{C}$ for $90 \mathrm{~min}$. 


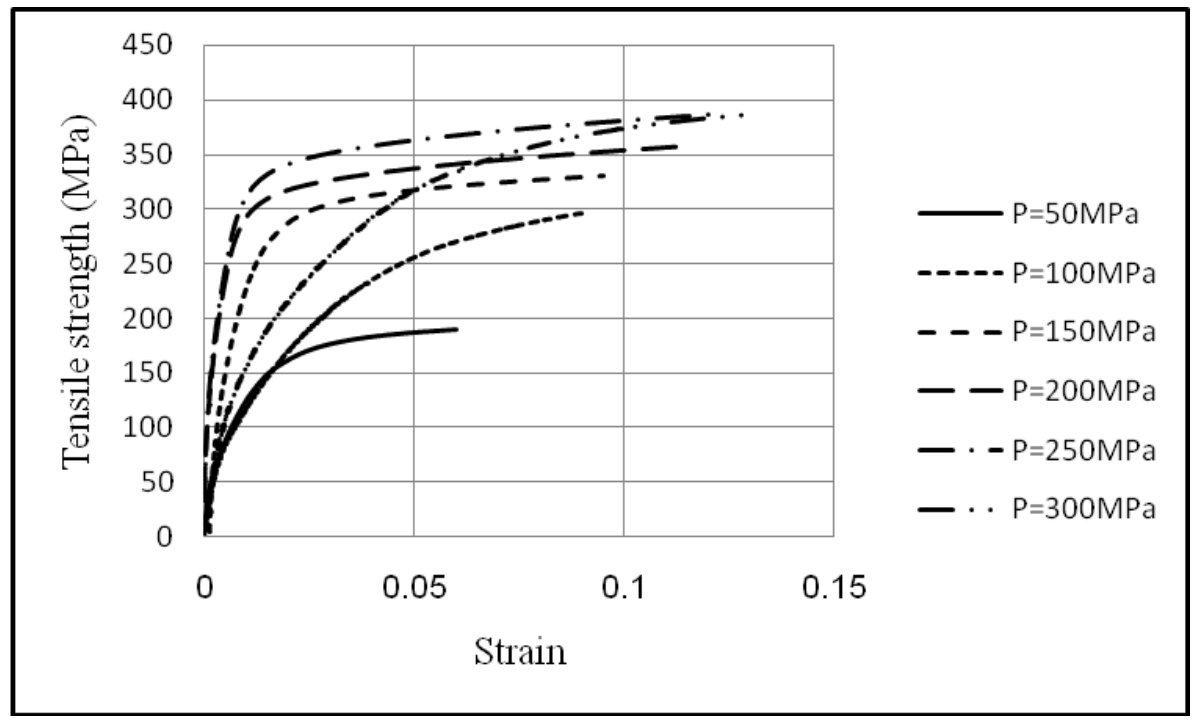

Fig.(12) Effect of compaction pressure on the stress strain diagrams of W-4.9Ni-2.1Fe alloy sintered at $1500^{\circ} \mathrm{C}$ for $90 \mathrm{~min}$.

To analyze the effect of compaction pressure and sintering temperature, as processing parameters, the ultimate tensile strength and ductility, obtained from the previous stress strain diagrams, were plotted against these parameters as shown in Fig.(13).
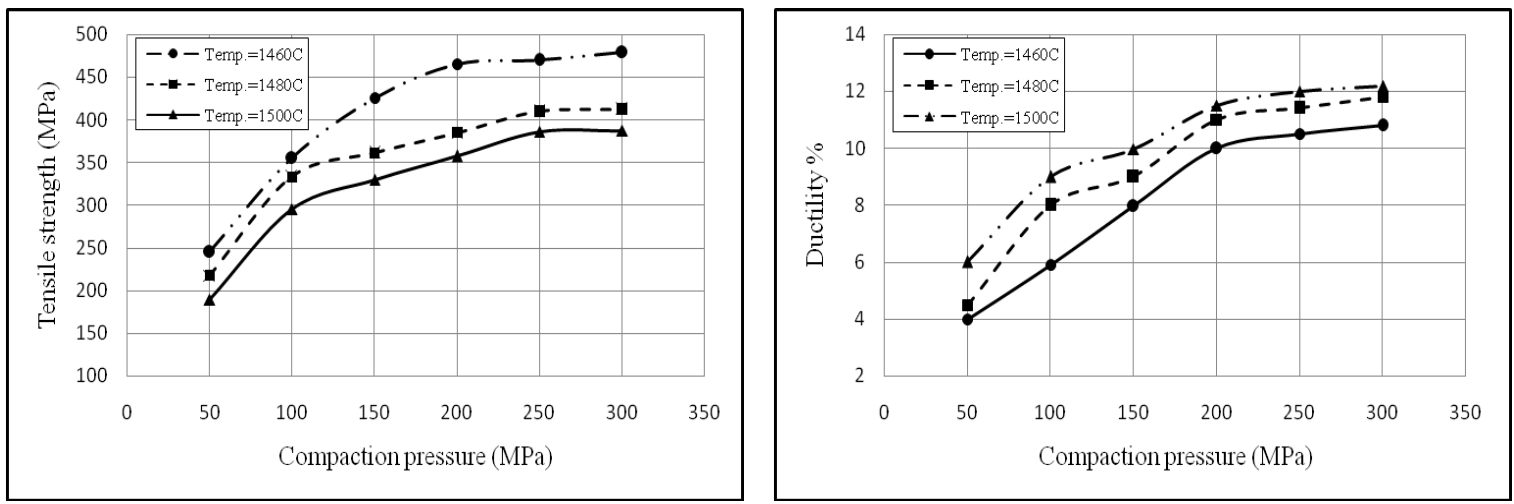

\section{Fig.(13) Tensile strength and ductility variations with compaction pressure and sintering temperature}

Both the ultimate tensile strength and ductility significantly increase, almost linearly, with the increase of compaction pressure up to about $200 \mathrm{MPa}$. This behavior can be attributed to the intense densification and substantial pore closure in this range of pressure. It was reported that [14] during the first stages of compaction, rapid densification occurs due to particle movement and rearrangement resulting in improved packing and the formation of new particle contacts. Subsequent increase in applied pressure leads to elastic and plastic deformations of powder particles resulting in increased mechanical interlocking and cold welding of particles. Higher pressures cause localized deformation giving work hardening and the homogenous plastic flow spreads to the entire particles causing a bulk deformation and work hardening. We can note that, at higher compaction pressures up to $300 \mathrm{MPa}$, less significant increase in strength and ductility can be revealed. 
Concerning the influence of sintering temperature. It was found that the ultimate tensile strength decreases while the resulting ductility increases, with increasing sintering temperature. These changes in tensile properties can be attributed to the variations that occur in microstructures. As the sintering temperature increases, the grain size and matrix volume fraction increase, while the contiguity decreases, as shown in the microstructure analysis. In this view, the evolution of the tensile properties can be interpreted as follows, at higher sintering temperatures, there are fewer but larger tungsten grains, more matrix volume fraction and consequently greater mean free matrix slip path for dislocation. As a result, the dislocation can move freely, for long distances, before intersecting a tungsten particle. This results in less work hardening, and leads to higher dutility and lower strength.

The effect of sintering time on the tensile properties was also invistigated on specimens of the same alloy at a fixed values of compaction pressure (200 MPa) and sintering temperature $\left(1500^{\circ} \mathrm{C}\right)$, as illustrated in Fig.(14), where the sintering time was varied from 30, up to 120 minutes.

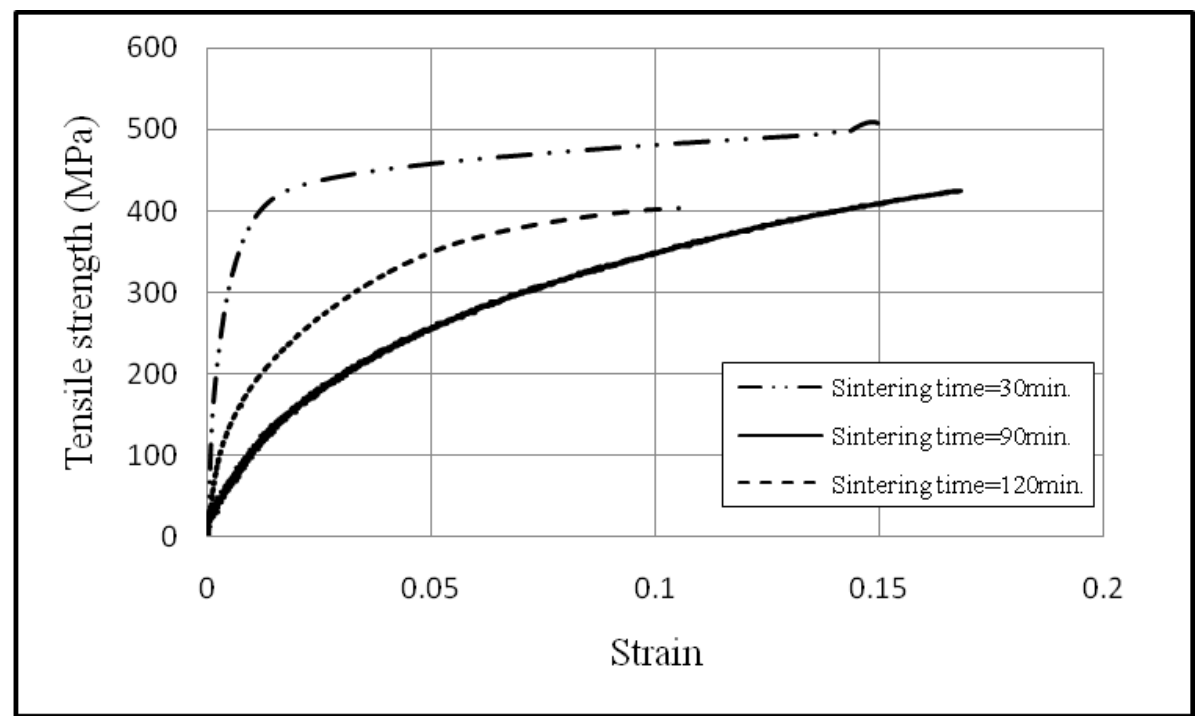

\section{Fig.(14) Effect of sintering time on the stress strain diagrams of W-4.9Ni-2.1Fe alloy compacted at $200 \mathrm{MPa}$ and sintered at $1500^{\circ} \mathrm{C}$}

The sintering time showed a similar effect to sintering temperature on ultimate tensile strength and ductility. Ultimate tensile strength decreases sensibly with prolonged sintering time, while, ductility increases linearly up to 90 minutes. Prolonged sintering times leads to significant grain growth and pore coarsening with degraded properties as shown in Fig.(15). These results are in accordance with work reported by R.M.German [15].
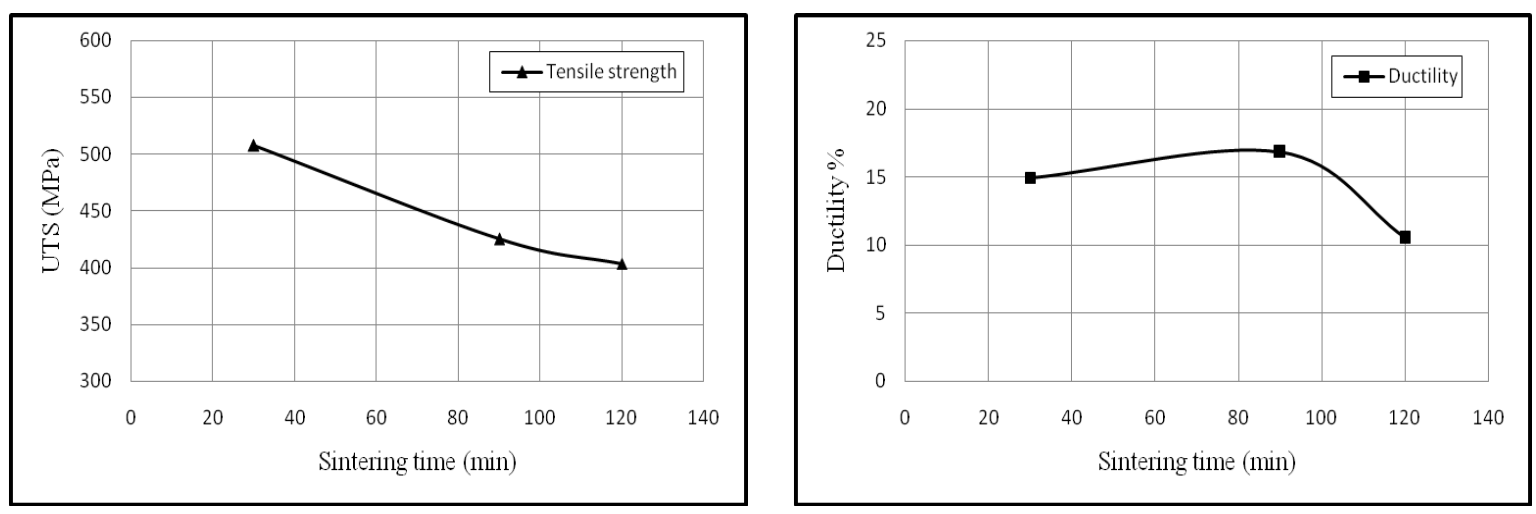

Fig.(15) Tensile strength and ductility variations with sintering time 


\subsubsection{Hardness}

The influence of compaction pressure and sintering temperature on hardness is shown in Fig.(16). The measured hardness was found to decrease with increasing the sintering temperature, which can, also, be explained by tungsten grain growth, and the increased matrix volume fraction. On the other hand, these hardness values showed a considerable increase, with increasing the compaction pressure, up to a certain maxima, where these values starts to decrease. This maxima is dependant on the sintering temperature, and is attained at lower values of pressures, at elevated sintering temperatures. This decrease of hardness at higher compaction pressures is explained by the entrapped gases effect inside closed pores that manifist, in the late stages of compaction, trying to escape out, and vent towards the surface. This leads to a decrease in hardness as a surface property more than other properties.

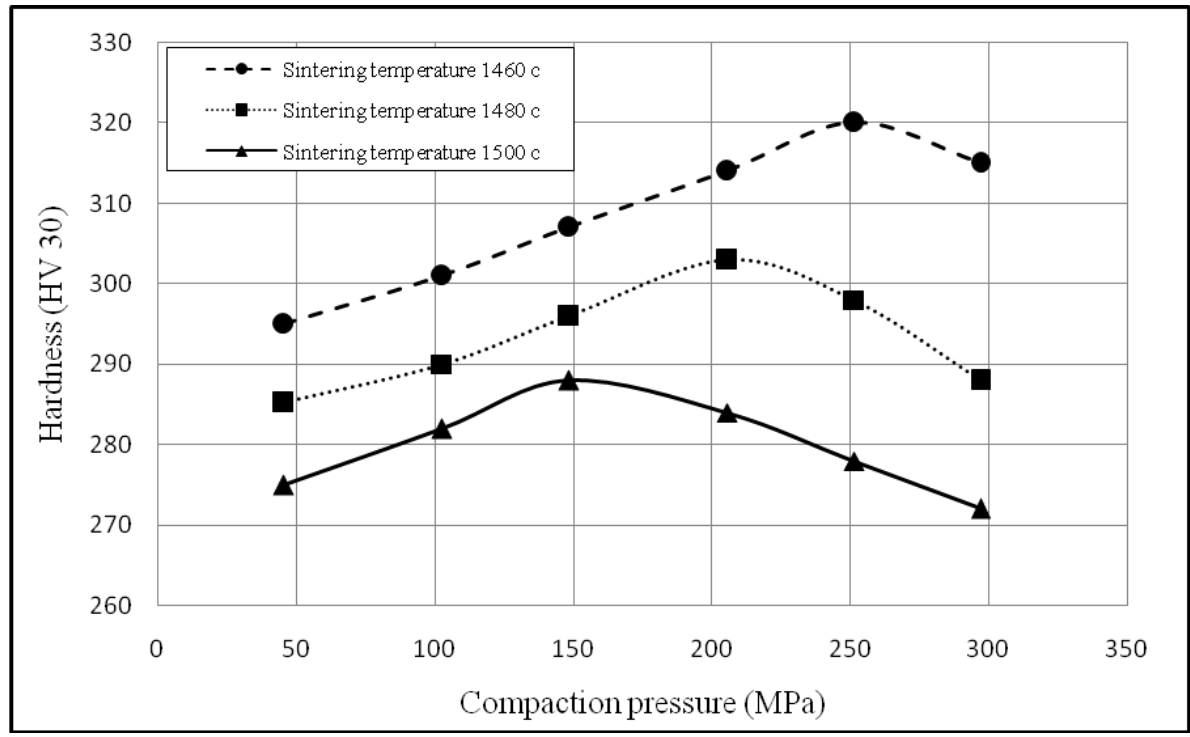

Fig.(16) Hardness variations with compaction pressure and sintering temperature

The influence of sintering time on the hardness is shown in Fig.(17). Hardness values decreases with prolonged sintering due to grain growth and increased matrix volume fraction.

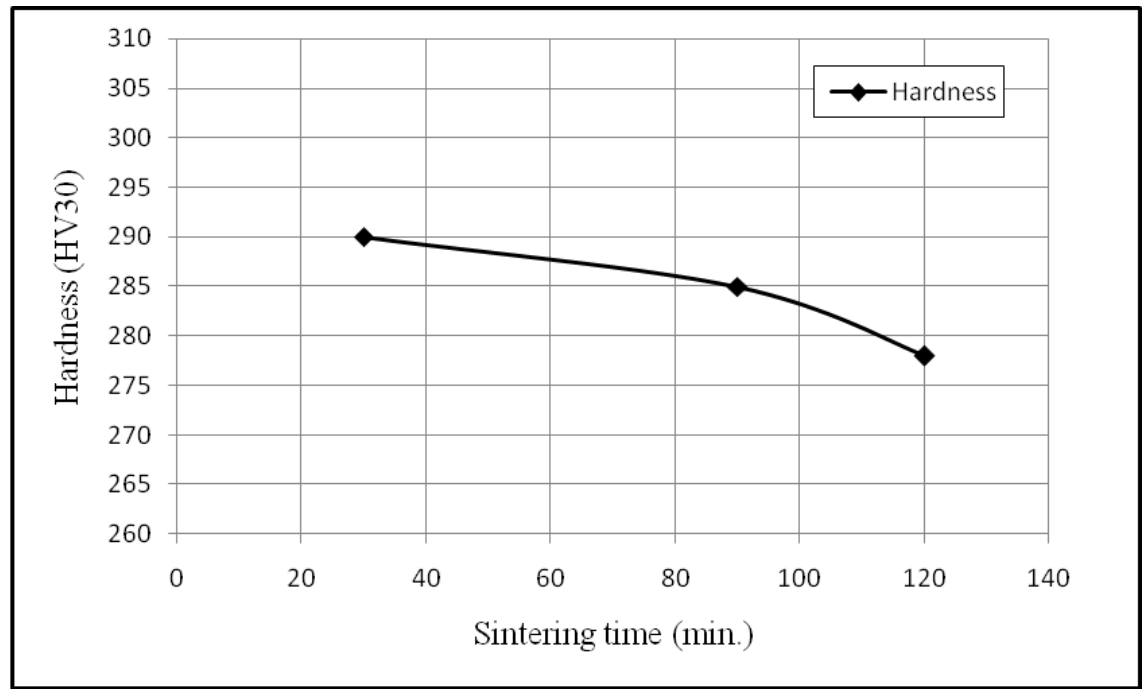

Fig.(17) Hardness variations with sintering time 


\subsubsection{Impact resistance}

Fig.(18) shows the influence of compaction pressure and sintering temperature on impact resistance. It can be noted that, the impact resistance increases, in a first stage, by increasing both compaction pressure and sintering temperature up to a certain maximum, where impact resistance starts to decrease, in a second stage. This behavior is closely similar to the ductility, but the toughness of the material is more sensitive to grain growth, which may explain the lower values obtained at sintering temperatures above $1480^{\circ} \mathrm{C}$.

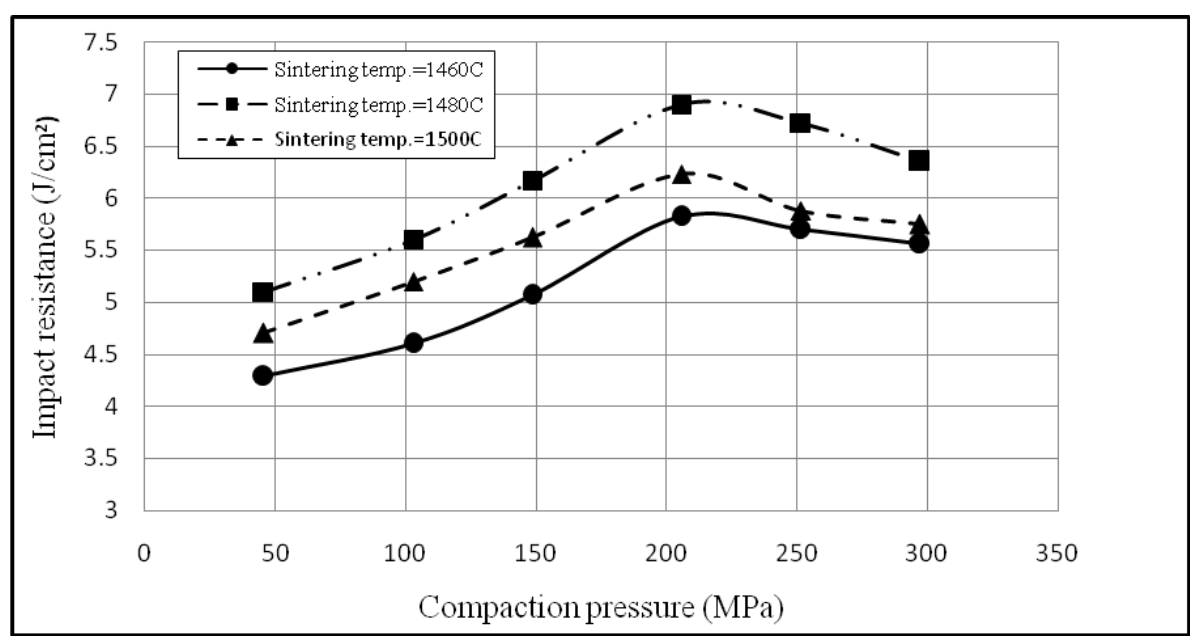

\section{Fig.(18) Impact resistance variations with compaction pressure and sintering temperature}

The influence of sintering time on the impact resistance is shown in Fig.(19). Impact resistance values decreases with prolonged sintering time due to grain growth.

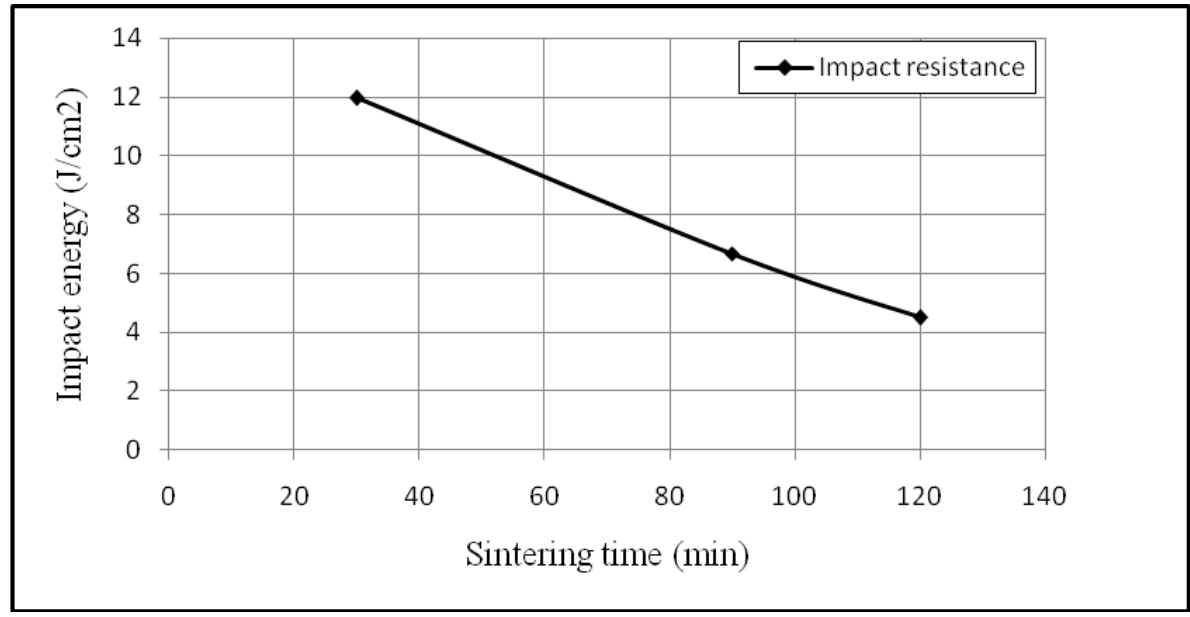

Fig.(19) Impact resistance variations with sintering time 


\subsection{Green and Sintered Density}

\subsubsection{Green denisity}

The measured green densities of compacts and their calculated relative values with respect to the theoritical density of the adopted mixture $93 \% \mathrm{~W}-4.9 \% \mathrm{Ni}-2.1 \% \mathrm{Fe}\left(18.551 \mathrm{gm} / \mathrm{cm}^{3}\right)$ are shown in Fig.(20). We can remark that the green density increases monotonically with increasing the values of compaction pressure up to $300 \mathrm{MPa}$. At this value of compaction pressure, the green density reaches $8.9 \mathrm{gm} / \mathrm{cm}^{3}$, and its relative value attains about $49 \%$ of the theoretical density of mixture.

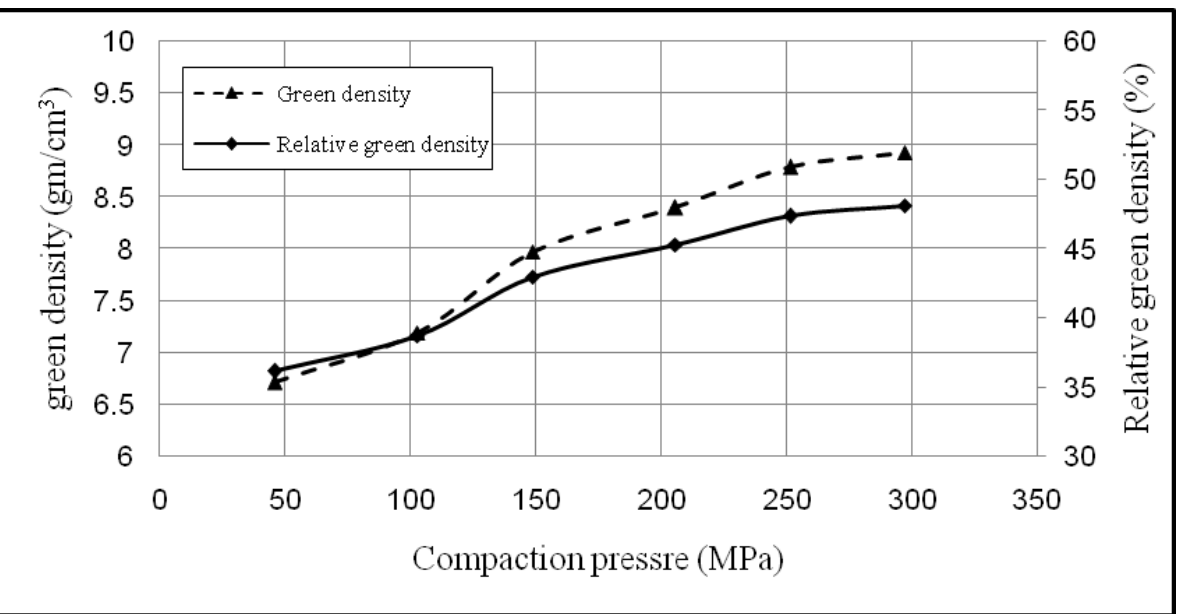

Fig.(20) Effect of compaction pressure on green and relative densities of compacts

\subsubsection{Sintered density}

The effect of compaction pressure and sintering temperature on the sintered density for the tungsten heavy alloy specimens, is illutrated in Fig.(21). Sintering was carried out under vacuum at different temperatures for a fixed sintering time of 90 minutes. We can note that, from one hand, the sintered density increases with incresing the sintering temperature, and from the other hand, an optimum maximum density of about $18 \mathrm{gm} / \mathrm{cm}^{3}$ can be obtained under a compaction pressure of $200 \mathrm{MPa}$ and a sintering temperature of $1500^{\circ} \mathrm{C}$.

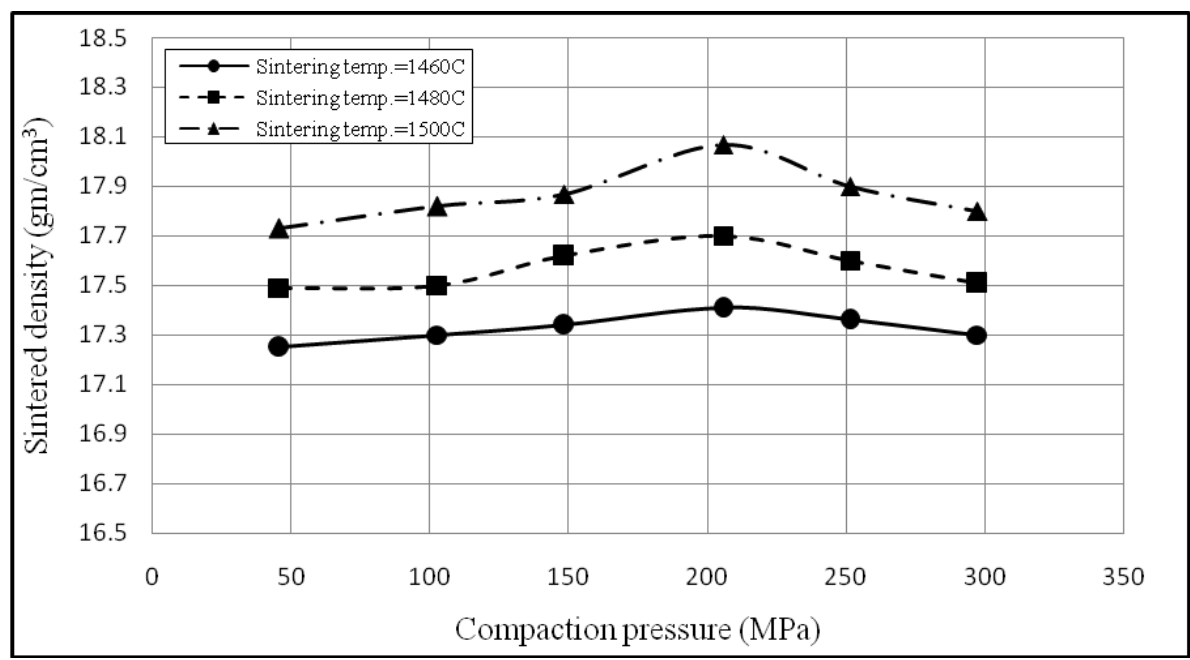

Fig.(21) Sintered density variations with compaction pressure and sintering temperature 
Moreover, the investigation of the effect of sintering time on the density of samples proved that prolonging the sintering time from 30 minutes up to 120 minutes increases the sintered density with about $4 \%$, when compaction is done under $200 \mathrm{MPa}$, and sintering is carried out at $1500^{\circ} \mathrm{C}$, as shown in Fig.(22).

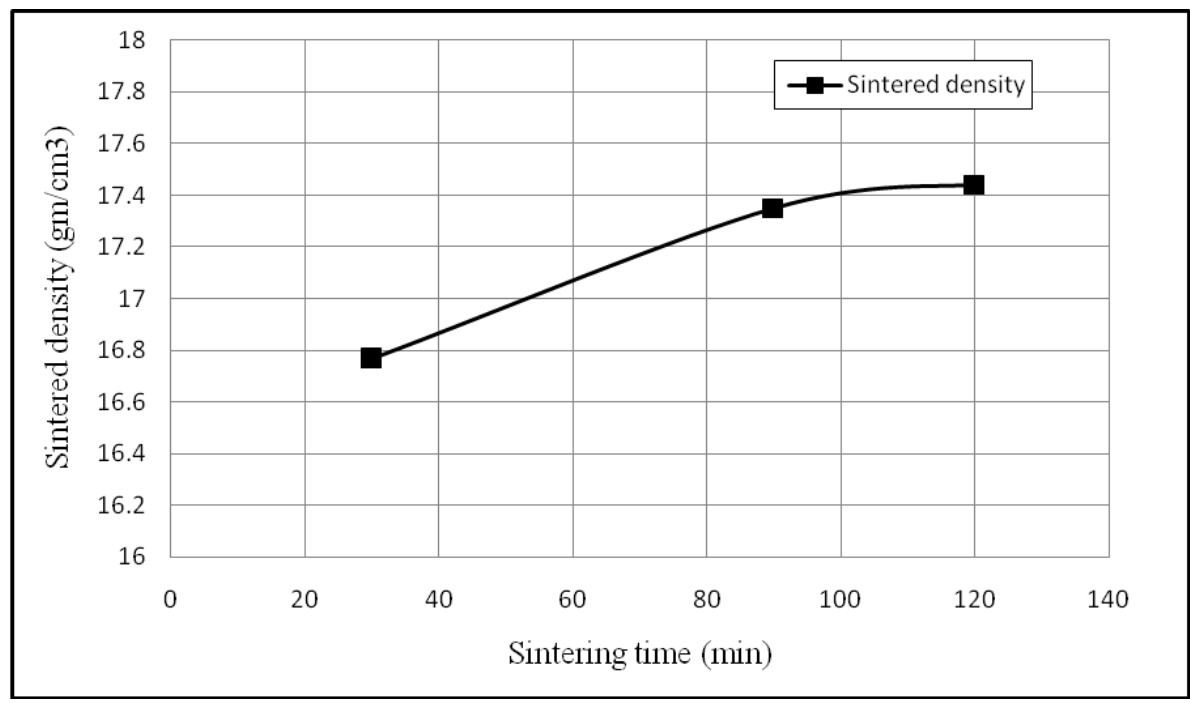

Fig.(22) Effect of sintering time on the sintered density of the tungsten heavy alloy, when compaction is done under $200 \mathrm{MPa}$, and sintering is carried out at $1500^{\circ} \mathrm{C}$

\subsection{Fracture Behavior}

There are four probable fracture mechanisms of liquid phase sintered tungsten heavy alloys, which are often, simultaneously present on the fracture surfaces of these alloys as illustrated in Fig.(23).

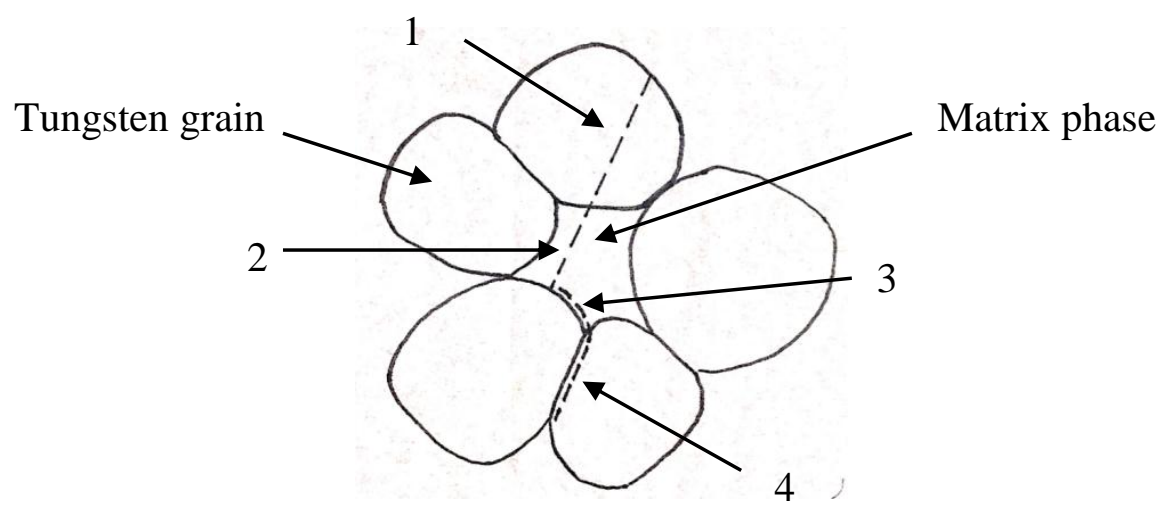

1- Tungsten grain brittle transgranular cleavage fracture

2- Matrix ductile dimple failure

3- Tungsten-matrix intergranular separation

4- Tungsten-tungsten grain boundary failure

Fig.(23) Schematic diagram representing all possible failure mechanisms and fracture paths of liquid phase sintered tungsten heavy alloys

The tungsten-tungsten interfaces are considered as the regions of the weakest bond [10], so that the fracture is generally initiated at the tungsten-tungsten interfaces. The proportion of tungsten-tungsten separation depends on the contiguity. As the contiguity increases the tungsten-tungsten separation increases, which is strongly related to tungsten concentration and grain size. 
The strength of the matrix, or the bonding strength of the interface between tungsten particles and matrix, was found to control, to a great extent, the nature of the final fracture [14].

When matrix strength or interfacial strength between tungsten particles and matrix are poor, the fracture initiates by separation either by matrix failure or by interface failure, which generally corresponds to low ductility and low strength.

When both, the matrix strength or interfacial strength between tungsten particles and matrix are stronger than the tungsten particles, fracture takes place predominantly by cleavage of tungsten particles, which generally corresponds to high strength of the alloys.

Fig.(24) illustrates the impact fracture modes obtained with specimens of 93\%W-4.9\% Ni$2.1 \%$ Fe uni-axially compacted under $200 \mathrm{MPa}$ and sintered at different temperatures for 90 minutes.

It can be stated that, at high sintering temperatures, the grain size became coarse and the dominant fracture mode is intergranular and matrix separation. On the contrary, when the sintering temperature is low, above the temperature specified for the liquid phase, the grain size is kept fine and the dominant fracture mode is transgranular cleavage separation. It was reported [16] that, tungsten grain size plays an important role in dictating the failure mode. If tungsten grain size is large, interface failure is predominant. However, as the grain size decreases, fracture mode changes gradually from interface failure to matrix failure and then to tungsten grain cleavage failure.

\section{Conclusion}

This study has determined the variations in microstructure and mechanical properties associated with the processing parameters of tungsten heavy alloy $93 \% \mathrm{~W}-4.9 \% \mathrm{Ni}-2.1 \% \mathrm{Fe}$ produced by uni-axial die pressing and vacuum liquid-phase sintering.

- The application of a compaction pressure of 200MPa provides optimum mechanical properties of the sintered compacts. For higher compaction pressures up to $300 \mathrm{MPa}$, no significant increase of properties can be revealed.

- The mean grain size and matrix volume fraction increase, while contiguity and connectivity decrease, with increasing sintering temperature and time.

- Maximum ultimate tensile strength, and hardness were obtained, after sintering at $1460^{\circ} \mathrm{C}$ for 30 minutes. Further increase of sintering temperature and time decreases the values of these properties.

- The ductility increases with sintering temperature up to $1500^{\circ} \mathrm{C}$, and sintering time up to 90 minutes due to the increased matrix volume fraction by the enhanced tungsten solubility. At higher temperatures and prolonged sintering time, this effect is counterbalanced by the excessive growth of tungsten grains.

- Sintering at an intermediate temperature of $1480^{\circ} \mathrm{C}$ for 30 minutes provides the highest toughness of this alloy.

- The sintered density increases monotonically with increasing both sintering temperature and time. However, the increase of compaction pressure up to $200 \mathrm{MPa}$, significantly increases the values of this density, higher values of pressures have minor effect. When sintering at $1500^{\circ} \mathrm{C}$ for 90 minutes, a maximum density of about $18 \mathrm{gm} / \mathrm{cm}^{3}$ can be obtained.

- When sintering is carried at high temperatures, the grain size became coarse and the dominant fracture mode is intergranular and matrix separation. On the contrary, when the sintering temperature is low, above the temperature specified for the liquid phase, the grain size is kept fine and the dominant fracture mode is transgranular cleavage separation. 

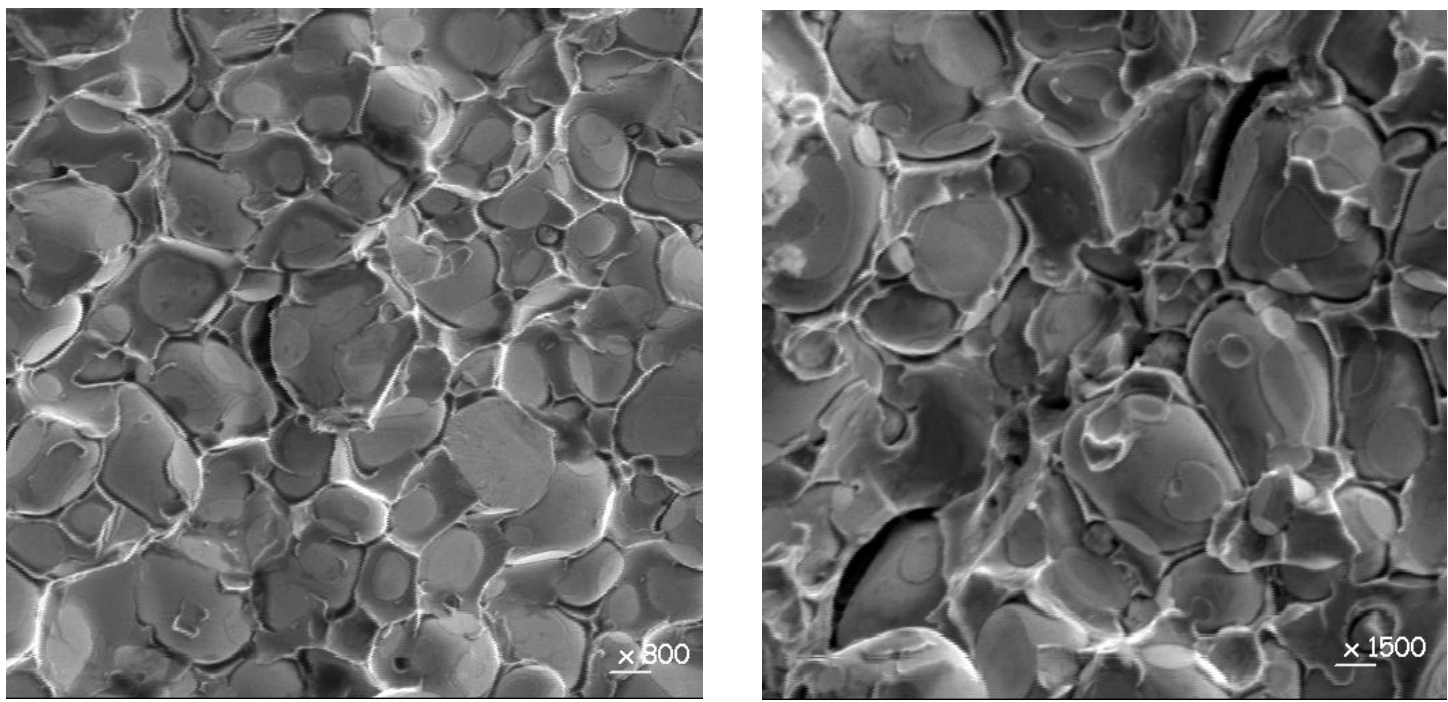

Coarse grained fracture with dominant intergranular fracture mode
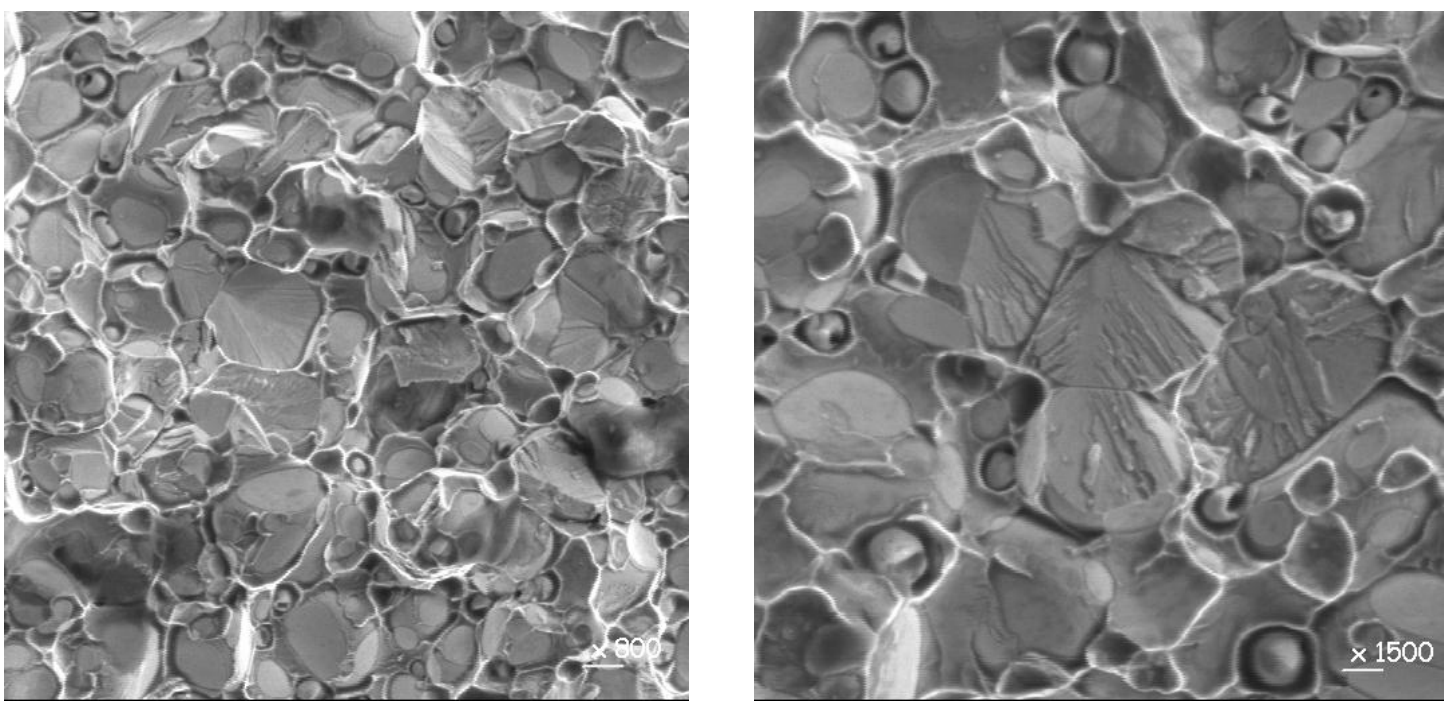

Average grained fracture with dominant mixed intergranular and cleavage fracture
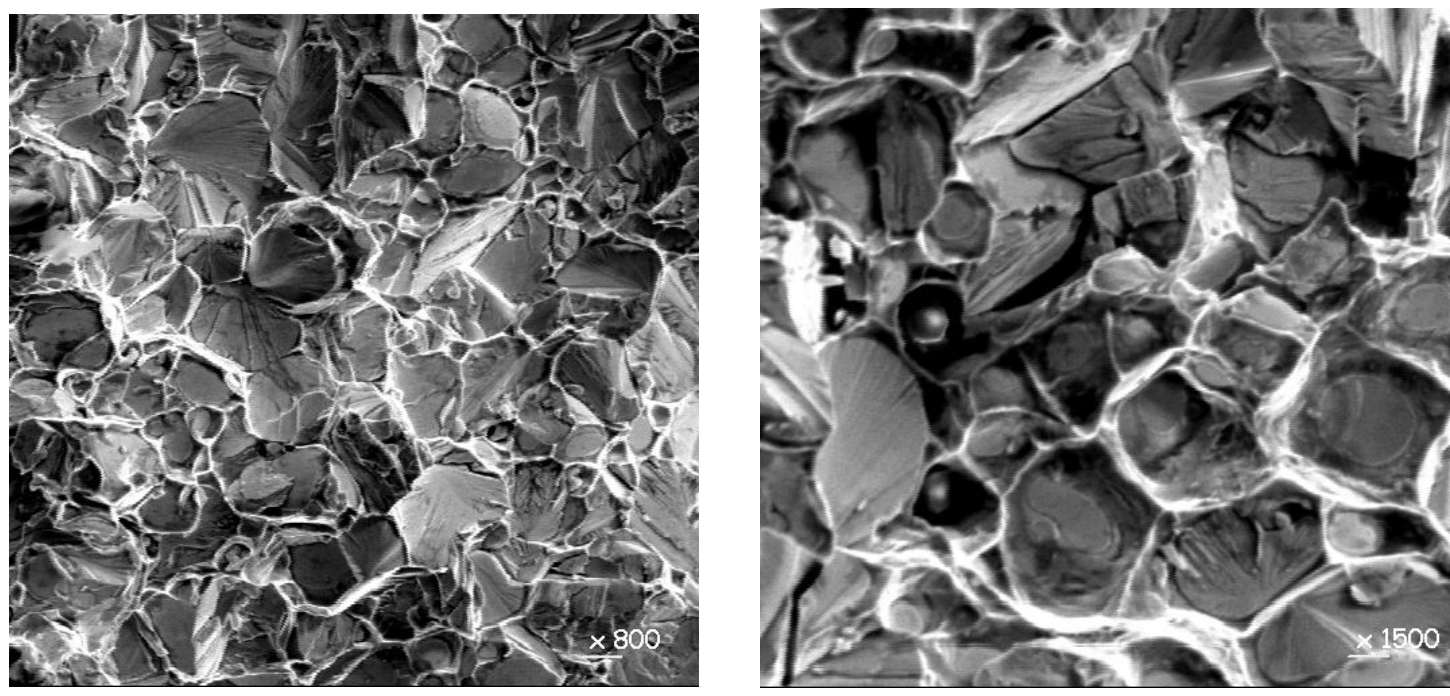

Fine grained fracture with dominant transgranular cleavage fracture mode

Fig.(24). Impact fracture modes for $93 \% \mathrm{~W}-4.9 \% \mathrm{Ni}-2.1 \% \mathrm{Fe}$ uni-axially compacted under $200 \mathrm{MPa}$ and sintered at different temperatures for 90 minutes. 


\section{References}

[1] C.Lea, B.C.Muddle, and D.V.Edmonds, "Segregation to interphase boundaries in liquid-phase sintered Tungsten alloys", Metallurgical Transactions A, Vol. 14A, April 1983, pp.667- 677.

[2] W.D.Cai, Yi Li, R.J. Dowding and F.A. Mohamed, "A review of tungsten based alloys as kinetic energy penetrator materials", Third international conference on tungsten and refractory metals, edited by A.bose and J.Dowding, 1995.

[3] W.Leonard, L.Magness Jr. and D.Kapoor, "Improving mechanical properties of tungsten heavy alloy composites through thermo-mechanical processing", Tungsten and tungsten alloys, edited by A.Bose and R.J.Dowding. MPIF, Princeton, NJ., 1992, pp.127.

[4] R.M.German, L.L.Bourguignon and B.H. Rabin, "Microstucture limitations of high tungsten content heavy alloys", International journal of powder metallurgy, Vol.37, No.8, 1985, pp.36,.

[5] B.H. Rabin, R.M.German and A.bose, "Characteristics of liquid phase sintered tungsten heavy alloys", International journal of powder metallurgy, Vol.25, No.1, 1989,pp.21.

[6] J.P. Wittenauer and T.G. Nieh, "Development of fine grained ductile tungsten alloys for Armor/Anti-Armor", AD-A231 857, Lockheed Missiles \&Space Company, Inc., Palo Alto, CA.

[8] B.H. RABIN and R. M. GERMAN, "Microstructure effects on tensile properties of tungsten-nickel-iron composites", Metallurgical Transactions A, Volume 19A, June 1988 , pp.1523.

[9] S. Humail Islam, F. Akhtar, S.J. Askari, M. Tufail, Xuanhui Qu, " Tensile behavior change depending on the varying tungsten content of $\mathrm{W}-\mathrm{Ni}-\mathrm{Fe}$ alloys", International journal of refractory metals \& hard materials, Vol.25, 2007, pp.380-385.

[10] X. Gong, J.L. Fan, F. Ding, M. Song, B.Y. Huang, "Effect of tungsten content on microstructure and quasi-static tensile fracture characteristics of rapidly hot-extruded $\mathrm{W}-\mathrm{Ni}-\mathrm{Fe}$ alloys", International journal of refractory metals and hard materials, Vol.30, 2012,pp.71-77.

[11] C 373, Standard Test Method for Water Absorption, Bulk Density, Apparent Porosity, by Boiling Water, Copyright ASTM, 1999.

[12] ASM metals handbook, "Metallography and microstructure", Vol.9, 1992.

[13] R.M. German, Powder metallurgy science. Pennsylvania state university, 1994.

[14] A. Fernandez, Guillermet and L. Ostlund, "Experimental and theoretical study of the phase equilibria in the Fe-Ni-W system Fe-Ni-W system", Metallurgical Transactions, Vol. 17A, October 1986, pp.1809.

[15] R.M. German, A. Bose, and S.S. Mani, "Sintering time and atmosphere influences on the microstructure and mechanical properties of tungsten heavy alloys", Metallurgical Transactions, Vol. 23A, January 1992, pp.211.

[16] J.Das, U. Ravi Kiran, A.Chakraborty and N.Eswara Prasad, "Hardness and tensile properties of tungsten based heavy alloys prepared by liquid phase sintering technique", International journal of refractory metals \& hard materials, Vol.27, 2009, pp.577-583. 